\title{
A escolarização de adolescentes em conflito com a lei: um estudo no Degase
}

\section{Raquel Rodrigues da Costa}

Diretora Adjunta de Unidade Escolar da Rede Estadual de Educação do Estado do Rio de Janeiro - SEE/RJ

José Jairo Vieira

Docente do programa de Pós-Graduação em Educação da Universidade Federal do Rio de Janeiro (PPGE-UFRJ)

\section{Andréa Lopes da Costa Vieira}

Docente do Programa de Memórias Social da Universidade Federal do Estado do Rio de janeiro (PPGMS-UNIRIO) 


\section{Resumo}

Frequentemente ouvimos expressões que destacam a escola e a educação sistemática como fatores determinantes na prevenção de atos infracionais, seja pela proteção do jovem em sua permanência no espaço escolar, pelos efeitos moralizadores operados pela escola ou pelas possibilidades futuras que se abrem a escolarizados. No entanto, os professores da rede pública de ensino se deparam com alunos que, após serem reprovados repetidas vezes, abandonam a escola e se envolvem em infrações, relatando ainda que o fracasso e a evasão escolar estão entre os principais fatores de risco para o desenvolvimento de conduta infracional. Este é um estudo de natureza qualitativa, que foi desenvolvido através de entrevistas com 05 jovens do sexo masculino, com idades entre 16 e 18 anos, escolhidos de forma aleatória, em medida socioeducativa de internação na Escola João Luiz Alves (JLA). Para tanto, foi necessário autorização da Divisão de Estudos, Pesquisas e Estágios (DEPE), da Escola de Gestão Socioeducativa Paulo Freire (ESGSE), que encaminha os pedidos de autorização ao juiz da Vara da Infância e Juventude, mediante a apresentação de projeto de pesquisa, com roteiro de entrevista e documento de confirmação de matrícula em Universidade, com autorização do Orientador e documentos do pesquisador. Não foi necessário pedir autorização aos pais e/ ou responsáveis dos jovens, pois quando em medida de internação, quem responde pelo jovem é o Estado, pois está sob sua guarda. Os resultados mostram que a escola não é o foco que diretamente facilita o ato infracional, no entanto representa, atualmente, em razão de falta de perspectivas e oportunidades, uma variável significativa nas aspirações de jovens e esta falta de perspectivas e oportunidades faz com que a escolarização não isente o jovem da prática de ato infracional, ou seja, a escola por si só não protege contra a conduta infracional.

Palavras-chave: Degase. Exclusão. Desigualdade social. Jovens em conflito com a lei. Medida socioeducativa. Escola. 


\section{Abstract}

Often we hear expressions that emphasize school and systematic education as determining factors in the prevention of infractions, whether for the protection of the young person in his / her permanence in the school space, for the moralizing effects operated by the school or for the future possibilities that are open to school children. However, teachers in the public school system are faced with students who, after repeated disapprovals, drop out of school and become involved in infractions, also reporting that school failure and dropout are among the main development risk factors of conduct. This is a qualitative study, which was developed through interviews with 05 male youths, aged between 16 and 18 years, randomly chosen as a socio-educational measure of hospitalization at the João Luiz Alves School (JLA). In order to do so, it was necessary to obtain authorization from the Division of Studies, Research and Internships (DEPE), from the Paulo Freire School of Socio-educational Management (ESGSE), which submits applications for authorization to the judge of the Childhood and Youth Court, research, with interview script and document of confirmation of enrollment in University, with authorization of the Advisor and documents of the researcher. It was not necessary to ask permission of the parents and / or responsible of the young people, because when in terms of hospitalization, the one who answers for the young person is the State, since it is in their custody. The results show that the school is not the focus that directly facilitates the infraction, but currently represents a significant variable in the aspirations of young people due to a lack of perspectives and opportunities. schooling does not exempt the youth from the practice of an infraction, that is, the school alone does not protect against the infractional conduct.

Keywords: Degradation. Exclusion. Social inequality. Young people in conflict with the law. Socioeducative measure. School. 


\section{Introdução}

Existe uma crença amplamente difundida de que a escola é um fator de prevenção contra a criminalidade. No entanto, os professores da rede pública de ensino se deparam com alunos que, após serem reprovados repetidas vezes, abandonam a escola e envolvem-se em infrações, relatando ainda que o fracasso e a evasão escolar estão entre os principais fatores de risco para o desenvolvimento de conduta infracional.

Embora o país exalte as melhorias no acesso à educação, ainda existem questões sérias a serem enfrentadas, como as elevadas taxas de evasão e repetência, a qualidade da educação oferecida, o desafio da construção da cidadania, os índices nem sempre satisfatórios de conclusão, entre outras.

Apesar de, atualmente, mais jovens e crianças frequentarem as salas de aula que no passado, a massificação do acesso à escola em nada garante o verdadeiro aumento de sua qualidade e eficácia. Se despreparada, a escola tende a reforçar as desigualdades que acolhe e acaba por trilhar um caminho entremeado de taxas de repetência e abandono que, finalmente, resulta em fracasso. Jovens que percorrem tal caminho, escasso em oportunidades culturais e de acesso ao mercado de trabalho, se tornam alvos potenciais da violência que acontece dentro e fora da escola e acabam, muitas vezes, tornando-se também autores dessa violência, em um ciclo vicioso.

Fazendo uma análise histórica das políticas de assistência para a infância e adolescência no Brasil pode-se observar mudanças tanto nas características nos grupos de crianças e adolescentes em conflito com a lei, quanto nas percepções que a sociedade constrói a seu respeito, tais quais as transformações da sociedade em que estão inseridos.

A fim de esclarecer o que classificamos como mudanças nas percepções podemos citar as formas como vieram se formando historicamente as alterações na própria denominação conferida a estes jovens: crianças desvalidas, criminosas (até a passagem para a República), menores (até a criação do Código de Menores de 1927), menores contraventores, criminosos, delinquentes (até o Código de Menores de 1979), menores infratores (até o Estatuto da Criança e Adolescente - ECA - em 1990) e adolescentes em conflito com a lei, atualmente.

A forma como essas crianças e adolescentes foram e são chamados contém em si a maneira como a sociedade os enxerga e a dificuldade apresentada pela mesma de identificá-los de novas e outras formas (mesmo hoje, após vinte e três anos da existência 
do ECA, a maioria das pessoas ainda classifica este público como menores delinquentes e/ou infratores). A forma como essas crianças e adolescentes foram e são chamados contém em si a maneira como a sociedade os enxerga e a dificuldade apresentada pela mesma de aceitá-los como parte constitutiva de si mesma. Assim, a cada período, novas denominações são propostas como forma de acolher ou "classificar" esse grupo que existe, mas que deve ser caracterizado como um grupo a parte. No presente trabalho a denominação utilizada será jovens em conflito com a lei, a exemplo do estudo realizado por Gallo \& Williams (2005), que defendem que essa denominação representa "uma condição temporária (está em conflito) e não uma condição permanente como no caso de adolescente infrator" (p. 83).

Para Espíndula \& Santos:

Essa mudança de concepção da criança e do adolescente como menor em situação irregular para pessoa que necessita de cuidados protetivos marca a passagem da Doutrina da Situação Irregular para a Doutrina da Proteção Integral (2004, p. 359).

Crianças e adolescentes são vistos como cidadãos de direito nessa nova concepção trazida pelo Estatuto da Criança e do Adolescente.

Da mesma maneira como os nomes atribuídos a esta parcela da população vêm se modificando, é possível que o perfil destes jovens também venha sendo alterado com o correr do tempo. E de forma tão rápida quanto os acontecimentos em seu entorno, levando tempo para que tais mudanças sejam percebidas.

Pode-se afirmar que uma transformação atualmente bem significativa no perfil dos adolescentes cumprindo medidas socioeducativas de internação no Estado do Rio de Janeiro está no âmbito da Educação, já que, segundo estudos (VERGILIO, 2009) aconteceu um aumento significativo no nível de escolarização destes jovens, especialmente, no segundo segmento do Ensino Fundamental e no Ensino Médio.

O modelo do jovem em conflito com a lei descrito por Vergílio (2009) em estudo que trata de temas relacionados com a juventude, a criminalidade e as medidas socioeducativas, o descreve como alguém proveniente de classe economicamente baixa, constituição familiar desestruturada, classificação da cor/raça declaradamente parda ou preta, morador de comunidades, sendo a maioria localizada em regiões metropolitanas, desassistidas pelo poder público e com nível de escolaridade nos primeiros anos do ensino fundamental (VERGILIO, 2009). Porém esse mesmo autor destaca que, em 
relação à escolaridade, esta situação vem se modificando, pois o nível de escolaridade desses jovens em conflito com lei vem subindo, situando-se, principalmente, no segundo segmento do ensino fundamental e no médio. De acordo com Feijó e Assis (2004), que afirmam que a educação aparece como variável condicionante do comportamento infracional. Vemos como a escola é posta como principal meio de se conseguir inserção social através do mercado de trabalho.

Diante dessa informação inquieta-nos saber como a escolarização tem influenciado na vida dos jovens em conflito com a lei, o que os estudos têm revelado sobre o papel da escola como fator de contenção ou de estímulo, em outras palavras, de proteção ou risco para a entrada ou permanência do jovem nos delitos? Que aspectos ligados à escolarização podem influenciar nessa escolha? Se, como atestado nos estudos apontados, o nível de escolarização dos jovens que tem enfrentado problemas com as leis tem aumentado, a escolarização não tem cumprido seu papel? Refletir sobre esses aspectos revela-se importante em um momento em que nos defrontamos com professores que, a cada dia mais, tem se queixado das dificuldades no exercício da profissão, e não no que diz respeito ao trabalho específico com os conteúdos escolares, mas sim das relações humanas, da (in)disciplina constantemente presente nas aulas; e, paralelo a isso, com o quadro de jovens que envolvem-se continuamente em conflitos com a lei. Investigar as relações que se estabelecem entre esses dois aspectos a partir do que vem sendo produzido e publicado pode auxiliar àqueles que trabalham com essa população a compreenderem melhor seus respectivos papéis e atuarem de forma mais consciente de sua relevância na vida desses jovens que, muitas vezes, por meio desses comportamentos, buscam chamar a atenção para si mesmos.

A pesquisa bibliográfica foi realizada de forma aberta por meio de busca de estudos científicos de fontes diversas, nacionais e internacionais, produzidos e publicados nos últimos 15 anos, unindo os termos delinquência, adolescência, escola, adolescentes e jovens em conflito com a lei. Não foi possível esgotar todas as fontes de consulta, e aqui apresentamos o resultado da busca realizada.

É relevante destacar que embora, no Brasil, já tenham sido "abolidos" os termos delinquência, infratores e haja uma forte tendência a classificar os jovens que passam por regime de internação, como "privados de liberdade" e que os termos "pena" e “crime” não possam ser aplicados a tal público (por serem inimputáveis) ainda assim, aqui, serão utilizados tendo em vista o vocabulário empregado nos estudos. Outro 
vocábulo presente nos estudos e que será utilizado é a violência quando trata de explicar o comportamento empregado pelo jovem ao infringir uma lei penal, ou seja, ao cometer um crime.

O objetivo do estudo é investigar, por meio de entrevistas com 5 adolescentes em conflito com a lei, em situação de internação em uma das unidades do Departamento Geral de Ações Socioeducativas (DEGASE), as possíveis influências da escola na história de vida de menores autores de atos infracionais que chegam a ser privados da sua liberdade e provisoriamente afastados do convívio com seus familiares.

Justifica-se a presente pesquisa, pois é necessário compreender o papel e a influência que a vida escolar exerce na história de vida de jovens autores de atos infracionais.

O texto está organizado da seguinte forma: inicialmente, no inicial apresentaremos questões a respeito do jovem em conflito com a lei e os fatores de risco e proteção. Em seguida, abordaremos o que os estudos dizem sobre a escolarização do jovens em conflito com lei e, posteriormente as pesquisas que indicam a escola como aliada na prevenção da criminalidade, para então, Por fim, apresentaremos a metodologia e os resultados e análises das entrevistas, juntamente cos as considerações finais.

\section{Questões a respeito do jovem em conflito com a lei. fatores de risco e proteção: família, escola e amigos}

De acordo com o Estatuto da Criança e do Adolescente (ECA), jovem em conflito com a lei é todo aquele com idade compreendida entre doze e dezoito anos incompletos autor de "conduta descrita como crime ou contravenção penal" (art. 103). A referida legislação considera o jovem menor de 18 anos como inimputável, ou seja, não pode ser condenado como um adulto, eliminando-se assim a culpabilidade do jovem, o que não significa deixar o autor de ato infracional imune às suas consequências devendo, porém, submetê-lo às normas da legislação especial. Essa, por sua vez, prevê medidas socioeducativas aplicáveis aos adolescentes. Segundo o ECA, essas medidas consistem em: 
- Advertência;

- Obrigação de reparar o dano;

- Prestação de serviços à comunidade;

- Liberdade assistida;

- Semiliberdade;

- Internação.

Os estudos no Brasil, como o feito por Vergílio (2009), que se propõem a traçar o perfil dos adolescentes em conflito com a lei ou até mesmo as políticas públicas para estes jovens destacam o papel primordial da escola como instituição social que contribui ou que deveria contribuir para a redução de atos infracionais.

Ao analisarmos o que pode levar um jovem a cometer um delito, muitos fatores se apresentam. Reduzir a análise a apenas um deles é simplificar uma situação que em si revela-se multidimensional. Fatores se complementam e se influenciam mutuamente.

Monares (2008) em uma análise da situação política econômica atual (no caso refere-se ao Chile, mas que não se diferencia do vivido em outros contextos neoliberais) reporta à marginalização que a sociedade infringe ao jovem de classe desfavorecida economicamente, que vive em uma sociedade que estimula o consumo, mas não lhe dá meios de satisfazer aquilo que é considerado pela mesma sociedade como padrão para ser aceito. Diante desse quadro, de uma sociedade que marginaliza aquele que não ostenta os bens de consumo e por não oferecer meios para que um dia venha a obtê-los, pois lhe é oferecida educação de baixa qualidade e as ofertas de emprego que lhe são dadas são de serviços pouco remunerados, o jovem pode encontrar nos atos delituosos formas de obter aquilo que a sociedade não lhe permite por meios lícitos. Segundo o autor:

La marginación, una de cuyas partes fundamentales es la carencia material, da lugar a lo que se podría definir como una situación de precariedad general y constante. Es decir, las condiciones estruturales de marginación se expresan en todos o casi todos los ámbitos de la vida cotidiana, al punto que pueden llegar a ser consideradas o internalizadas por quien las vive como normales y sin mayores posibilidades de variación (p.5). 
Para alguns daqueles que não se conformam, cometer ações delituosas pode ser a forma de suprir a carência material, que embora satisfaça parte dos desejos impostos pela sociedade, não cobre a sensação de marginalização, apresentada constantemente "en todos o casi todos los ámbitos de la vida cotidiana"(p.5). Nesse contexto, os jovens buscam agrupar-se entre iguais, na busca por uma identificação, formando o que o autor chamou de espacio cultural. Nesses grupos, cometer atos delituosos pode significar maior reconhecimento, o que reforça a ação praticada. $\mathrm{O}$ autor é cuidadoso ao afirmar que essa explicação para a infração é uma das possíveis e não esgota todo o assunto e assume que não são todos os jovens que passam por essas situações que praticam atos delituosos. A análise apresentada pelo autor trata de aspecto relevante ao assunto, pois tira o foco do indivíduo, culpabilizando-o unicamente pela escolha, trazendo para a sociedade sua parcela de participação da questão dos jovens em conflito com a lei. Para além do apresentado pelo autor, reforçamos que não apenas os atos são cometidos como forma de obter o que lhes é negado, como também, para alguns desses jovens, a vivência cotidiana da marginalização leva a um sentimento de frustração e revolta, que, muitas vezes é manifestada também por atos delituosos, algumas vezes contra o patrimônio, outras contra as pessoas que representam o ideal social a que não pode alcançar. Com essa análise não se busca retirar a responsabilidade do jovem, mas sim, compreender sua ação de forma menos restrita, menos individual, menos de culpabilização apenas do sujeito e sua família, como normalmente se faz - provavelmente por ser mais simples e menos comprometedor - não que essas instâncias não sejam relevantes, como veremos a seguir, mas ampliar o olhar para outros fatores igualmente importantes.

Outro aspecto comum encontrado nos estudos sobre os jovens em conflito com a lei é o perfil desses jovens, como no estudo apresentado por Priuli e Moraes (2007) que traçam, a partir dos prontuários, o perfil socioeconômico de jovens acautelados em uma unidade da antiga FEBEM, atual Fundação Casa, em São José do Rio Preto. Neste estudo encontramos a ratificação das características apontadas na maioria da literatura a respeito deste público:

(...)ensino fundamental incompleto, evadido da escola, sem trabalho e residente na (...) de menor poder socioeconômico. A infração de maior percentual foi roubo, seguida de furto, (...) A maioria usava tabaco, maconha, álcool, crack;... Detectou-se realidade precária de familiares com baixo nível de renda, escolaridade, profissão e abuso de álcool, contribuindo para transformar os adolescentes em vítimas. A maioria 
das mães, provedora do lar, principal figura na internação e mediadora entre o adolescente, o poder judiciário e a comunidade. (PRIULI E MORAES, 2007, p. 7).

Esse perfil traçado corrobora com as características apresentadas anteriormente e não é difícil inferir que esses jovens a que se referem esses autores são os marginalizados descritos anteriormente. São jovens evadidos da escola, de classe econômica baixa que comentem principalmente roubo, provém de família de baixa renda, que não lhe possibilita o acesso aos bens de consumo tão desejados pelos jovens e que lhes definem o papel social. Nas famílias também há abuso de álcool, possivelmente fruto da própria frustração vivida pelos pais. É notório que nas instituições de internação esse perfil é o maioritário, isso pode levar a um leitor menos cuidadoso a considerar que a pobreza liga-se diretamente a violência. Sobre esse assunto Monares (2008) também se manifesta:

\footnotetext{
Asimismo, no se deben confundir las consecuencias criminógenas que la marginación puede tener en algunos/as jóvenes marginados/as, con la identificación de ellos/as como naturalmente criminógenos/as o propensos/as a mostrar comportamientos "desviados". Aceptar que hay una tendencia a la maldad inherente e inexorable en grupos determinados es una vuelta al evolucionismo social del siglo XIX. El cual, fuera de ser una mala teoría científica, también tenía tras de sí una específica concepción política que la hacia y la hace todavía moralmente cuestionable. (p. 7, grifo do autor).
}

A violência vivenciada ou executada na escola também pode ser um fator de estímulo ao comportamento infrator. Estudo realizado por Garcia \& Madriaza (2005) busca compreender os sentidos e significados da violência escolar manifestado do ponto de vista de jovens estudantes chilenos de 14 a 21 anos provenientes de diferentes classes sociais. Foram realizadas entrevistas e grupos focais e a principal justificativa dada pelos jovens para a questão "por qué la violencia" foi estabelecer hierarquia, ou seja obter respeito, status no grupo de pares, de ser visível aos colegas. Essa resposta reflete a necessidade dos jovens de serem reconhecidos e quando isso não é feito de maneira considerada adequada socialmente, pode ocorrer por meio de violência, ou quiçá, de um ato infracional. Um segundo ponto levantado foi a violência como defesa, de si, de um outro ou mesmo de um território, ainda fortemente ligado a imagem de si construída para o grupo. Os outros sentidos e significados diziam respeito a forma de resolver um 
conflito, como forma de catarse, para causar dano, para entreter-se, como forma de reinvincações sociais, de rebelar-se contra a autoridade. Segundo os autores:

\begin{abstract}
Asimismo, no se deben confundir las consecuencias criminógenas que la marginación puede tener en algunos/as jóvenes marginados/as, con la identificación de ellos/as como naturalmente criminógenos/as o propensos/as a mostrar comportamientos "desviados". Aceptar que hay una tendencia a la maldad inherente e inexorable en grupos determinados es una vuelta al evolucionismo social del siglo XIX. El cual, fuera de ser una mala teoría científica, también tenía tras de sí una específica concepción política que la hacia y la hace todavía moralmente cuestionable. (p. 7, grifo do autor).
\end{abstract}

Certamente nessa busca, sentir-se marginalizado por esse mundo que ainda não reconhece como um todo é um fator de insegurança, e que pode levá-lo a cometer infração.

\title{
A escolarização de adolescentes em conflito com lei
}

No grupo dos estudos que delineiam o perfil dos adolescentes encontramos a pesquisa de Assis e Souza (1999) a respeito dos fatores de prevenção da "delinquência" realizada por meio de entrevistas com jovens infratores do Rio de Janeiro e de Recife, bem como de seus irmãos que não cometeram atos infracionais. Este estudo baseia-se no modelo teórico proposto na obra Teorias da Delinquência. Analisando a justificativa de condutas delinquentes de Schomaker (1996), o autor se propõe explicar a origem da conduta criminosa do jovem a partir de três níveis: estrutural, sociopsicológico e individual. No nível sociopsicológico se encontram, de acordo com o autor, os estímulos mais significativos à delinquência e é onde se situam as instituições família, igreja e, obviamente, a escola. Se o controle exercido pelas instituições sociais falha, a conduta resultante poderá ser a prática de ato ilícito. Neste nível também se encontram os pares, em relações que podem ter sido estabelecidas nos espaços destas instituições, também se tornarem influências. A respeito da escola destacaram que: 
Mais de 70\% de todos os jovens entrevistados já tinham abandonado os estudos no momento da entrevista. O principal motivo alegado foi a necessidade de trabalhar e a dificuldade de conciliar escola com trabalho, seguido pelo desentendimento com professores e colegas, incluindo agressão física. A dificuldade da supervisão familiar, no que se refere à frequência escolar do jovem, ficou evidente. (ASSIS E SOUZA, 1999, p. 3).

Esses dados nos levam a reflexão sobre o porquê esses jovens apresentam tanta dificuldade em manter-se no ambiente escolar. Quais razões os fazem abandonar a escola? Será que as escolas estão preparadas para lidar com esses jovens que, desde muito cedo apresentam atitudes de enfrentamento? Será que sua exclusão dos bancos escolares é a melhor saída para eles mesmo e, por que não, para a sociedade como um todo?

Espíndula \& Santos (2004) realizaram estudo com assistentes de desenvolvimento social (ADS) que trabalham nas unidades de internação de jovens em conflito com a lei em Recife - PE, sobre as representações sociais que estes apresentam em relação aos jovens assistidos. A premissa do estudo foi a de que, a forma como os ADS veem os jovens influencia na forma como se relacionam com eles. Dado interessante observado no estudo e que se relaciona com o texto aqui apresentado, foi que esses assistentes não acreditam na recuperação dos internos e em suas representações, esses adolescentes são diferentes dos outros que não cometeram delitos. Transportando esses dados para a situação da escolarização, é possível que os mesmos fossem obtidos junto aos professores das escolas. Esses jovens que frequentam escolas, mas que apresentam comportamentos destrutivos talvez fossem também vistos como irrecuperáveis, diferentes dos outros que bem se comportam, numa análise de responsabilização do próprio sujeito. Uma questão poderia ser colocada sobre o quadro: como os jovens poderão recuperar-se se não forem alteradas as condições que os levaram a tais atos? Importante ressaltar que com essa análise não buscamos a culpabilização do professor, que também é sujeito e vítima dos contextos sociais, mas buscamos sim uma reflexão sobre o quadro que se mostra a respeito do perfil dos jovens em conflito da lei e da escola nesse contexto.

Em uma pesquisa de Gallo e Willians (2008) na qual é traçado o perfil de adolescentes, de ambos os sexos, que cumprem medidas socioeducativas em meio aberto e são assistidos por uma ONG, após análise dos prontuários destes adolescentes concluiu-se que os jovens que não frequentavam a escola registraram índices maiores de 
reincidência, uso de drogas e emprego de armas de fogo. Aqueles com maior escolarização viviam com ambos os pais e cometeram infrações equivalentes a crimes menos graves. Em contrapartida, os jovens que tinham menor escolarização viviam em famílias monoparenteais (em geral, chefiadas pela mãe) e cometeram atos infracionais mais graves. Nas considerações finais, os autores afirmam que o menor nível de escolaridade é um fator bastante relevante e apontam que este problema está sempre atrelado a outras variáveis como uso de drogas, escolas exclusivas e famílias monoparentais, devendo estes fatores serem considerados para que se obtenha êxito na recuperação e redução do número de adolescentes que cumprem medidas socioeducativas.

Gallo e Williams (2004a; 2004b) apresentaram dados que corroboram com a baixa escolaridade dos adolescentes em conflito com a lei. Em um levantamento do perfil do adolescente em conflito com a lei em uma cidade do interior de São Paulo, $60,2 \%$ dos adolescentes não frequentava a escola; outros 61,8\% tinham cursado da $5^{\mathrm{a}}$ à $8^{\text {a }}$ série do Ensino Fundamental e 27,6\% tinham cursado até a $4^{\text {a }}$ série do Ensino Fundamental. Segundo o relato desses jovens, cuja média de idade foi de 15,9 anos, os motivos que os levaram a abandonar as aulas foram: desinteresse $(43,2 \%)$, abandono $(13,5 \%)$, conflitos com outros alunos e/ou professores (13,5\%), fracasso escolar $(5,4 \%)$ e suspensão das aulas $(1,3 \%)$.

\footnotetext{
Se for considerado que essas categorias poderiam ser agrupadas em uma mesma categoria, pois estão relacionadas com as dificuldades que as escolas têm para lidar com esses alunos, tem-se $76,9 \%$ dos adolescentes. (GALLO e WILLIAMS, 2004, p. 86).
}

Sobre os dados apresentados nos estudos supracitados, vemos o contexto social como fator relevante, não é apenas a família monoparental, mas o que isso acarreta para o contexto familiar: uma mãe que necessita trabalhar para sustentar os filhos, já que é a única provedora, filhos que ficam sob a guarda de alguém externo, que pode ser um familiar próximo, um conhecido, ou mesmo sob o cuidado de si mesmos (VALENCIA, 2011), ou seja, sob baixa supervisão, inclusive em relação a escolaridade dos menores, que, muito cedo, devem abandonar a infância para ajudar no sustento da casa, ou na sua manutenção (VALENCIA, 2011). Com fonte de renda baixa, as consequências inevitáveis do estresse pela subsistência, um quadro propício para ser denominado como 
fator de risco para a inserção na vida delituosa. Diante disso, quais as motivações encontradas pela criança ou adolescente em frequentar a escola?

Em estudo que reflete sobre o papel da escola na vida desses jovens, Feijó e Assis (2004) afirmam que a educação aparece como variável condicionante do comportamento infracional através da segregação cultural ou da étnica, pois o indivíduo acredita que é incapaz e/ ou inferior em relação aos colegas e isto o impede de participar de forma plena na escola. A escola é também, posta como principal meio de se conseguir inserção social através do mercado de trabalho e as autoras explicam a importância da vinculação com o mercado de trabalho, consequência do atrelamento com a escola, para a inclusão social dos indivíduos por meio da teoria de Castel (apud Feijó e Assis, 2004) na qual o autor classifica como mais vulnerável aquele não inserido pelo mercado de trabalho. O autor explica que o excluído pelo trabalho está mais fragilizado do que aquele com problemas no eixo sociofamiliar.

A respeito da escolaridade, mais uma vez foi reafirmada a proposição de que quase a totalidade dos jovens em conflito com a lei encontra-se fora da escola, bem como que a maior parte possui Ensino Fundamental incompleto. É importante ressaltar que a referida publicação também assinala a "ausência" ou pouca participação dos pais na vida escolar dos filhos através de atitudes como a falta de cuidado com a frequência às aulas e permissão para que os filhos não estivessem nas escolas. A pesquisa mostrou ainda certa tendência dos filhos em reproduzir as trajetórias e atitudes dos pais, ocorrência esta que também explica todos os jovens estarem fora da escola já que os empregos dos pais também indicam que estes têm baixa escolarização.

Essa "naturalização" e aceitação do destino em relação à situação foi apontada por Valencia (2011) e se apresentava no discurso dos próprios jovens em regime de internação por ela entrevistados. Outros motivos apontados foram: presença de amigos, aprendizagem por imitação, curiosidade, evasão dos problemas, fazer-se visível e obter reconhecimento dos colegas. Já, muitos adultos, justificam as ações dos menores como "loucuras da adolescência". Vemos nas motivações apontadas a presença constante do outro, do entorno social, familiar ou do grupo de pares e também do contexto social mais amplo, na realidade vivida pelo jovem. Como afirma a autora: "el mundo delincuencial, no aparece de manera espontánea. Hunde sus raíces en la trayectoria vital, y ocupa un lugar en la experiencia cotidiana, naturaliza las actuaciones y las llena de contenido emocional" (VALENCIA, 2011, p. 25). 
Em outro estudo, Costa e Assis (2006) destacam a falta de instrumentos e atendimentos eficazes a este momento para a vida deles e que deem oportunidades de mudanças das variáveis que os fragilizam e enfatizam três fatores fundamentais para promover o sucesso destes adolescentes e que perpassam o espaço da escola, seja através do conhecimento adquirido, das relações e vivências que nela se estabelecem:

(...) fortalecimento de vínculos, autonomia e projeto de vida pode resultar na aquisição de outros importantes recursos para que adolescentes em situação de risco social desenvolvam a capacidade de resistir à destruição e a capacidade para se reconstruir, que constituem os dois componentes básicos da resiliência. (COSTA E ASSIS, 2006, p. 5).

Também são importantes os estudos em que os focos são as considerações sobre a criminalidade praticada por adultos. Pesquisar a criminalidade entre os adultos é entender a trajetória de vida desses indivíduos que foram adolescentes e, muitas vezes, foi a partir deste momento que começaram a praticar atos ilícitos. No estudo de Marino (2002) são identificadas as possíveis causas para reincidência de crimes a partir de variáveis socioeconômicas, da modalidade do crime e das características das prisões. A respeito da escola, o autor constata o aumento da escolarização da população carcerária através da diminuição dos analfabetos e daqueles com Ensino Fundamental incompleto e aumento dos que tem este último completo e Ensino Médio. No entanto, Marino acresce que este fato pode ligar-se ao recidivismo criminal seja através da escolarização dentro da prisão ou quando não são ainda punidos.

\section{A escola como aliada na prevenção da criminalidade}

Cano (2006) publicou um estudo com foco principal nas atuações e propostas das polícias e agentes de segurança das diversas esferas públicas e não deixou de considerar a educação como fator de "prevenção social". O autor prescreve políticas para ação em relação à escola: 
(...) projetos educativos, para aumentar a escolaridade dos jovens e evitar a evasão escolar, aumentando assim suas opções profissionais e pessoais; projetos de formação profissional para os jovens, com a mesma finalidade; (...) projetos culturais e recreativos dirigidos à juventude. Um exemplo são as atividades culturais organizadas nas escolas depois das aulas. (CANO, 2006, p. 55).

O estudo de Assis e Souza (1999) apresenta os resultados de estudos internacionais a respeito do tema por serem insuficientes as pesquisas no Brasil. Encontramos, com designações diversificadas, a intervenção da e na escola em todas as referências: para Dryfoos (apud Assis e Souza, 1999) como ambiente privilegiado na precaução de conduta ilícita; suprimento de oportunidade para Spergel e Curry (apud Assis e Souza, 1999); e ao resumirem em itens as propostas dos estudiosos relacionam a escola diversas vezes

\footnotetext{
(...) oferecer alternativas para o envolvimento dos jovens das gangues, como programas recreacionais, eventos escolares, trabalho; deve ser conduzido nas próprias comunidades dos jovens, envolvendo as famílias e a escola; ...procurar associar-se ao mundo do trabalho, propiciando oportunidades de treinamento profissional e emprego; seus objetivos devem ser específicos e resultar em alguma forma oficial de sucesso, como por exemplo, um diploma; (ASSIS E SOUZA, 1999, p.8).
}

Assis e Constantino (2005) delineiam, no estudo já citado, o cenário nacional das condições dos jovens em privação de liberdade e também das táticas de prevenção de atos infracionais. Na referida pesquisa, é retomada a variante educação, ou melhor, "falta de qualidade de ensino" como fator importante na prática de atos infracionais. O estudo destaca também as diferentes estratégias internacionais para a solução do problema (mostram a tendência a maior investimento nas polícias, aumento de número de prisões, do que em programas para prevenção ao uso de drogas e atos de violência). As autoras fazem uma linha do tempo das políticas de prevenção e afirmam que até a década de 60 do séc. XX a sociedade investiu no "tratamento e reabilitação de adolescentes" buscando "valorizar o potencial de modificação do comportamento e da adaptação social". Até a década de 1990 se priorizou a repressão. Na referida década retoma-se a "reabilitação" com novos programas de prevenção e diferentes metodologias e referenciais. 
Segundo as autoras, boas táticas são as resultantes de estudos de pesquisadores estrangeiros, em sua maioria. Algumas dessas medidas propõem intervenções diretas (centralizados na escola) e indiretas (perpassam pela escola) em vários aspectos das escolas, como: inserção desde a pré-escola para famílias em situação de risco e programas de prevenção de crimes e violência na escola

\footnotetext{
Visam prover estimulação intelectual, aumentar as habilidades cognitivas e aumentar o sucesso acadêmico futuro. Estudos com essa finalidade mostram consistência nos bons resultados de sucesso escolar, fator de risco importante para a delinquência. (ASSIS E CONSTANTINO, 2005, p. 6).
}

Porém, como apresentado por Valencia (2011) em estudo realizado com jovens internos, embora as medidas legais tenham como objetivo reabilitar o menor, o que se vê na prática são altos índices de reincidência entre os jovens que foram atendidos em regimes de internação. Nesses contextos de internação os jovens acabam aprendendo novos delitos com seus pares "mais experientes".

Nas considerações finais do estudo destacam ainda a importância de não se focar só no momento em que o adolescente cometeu a infração, mas na infância e enfrentando os múltiplos fatores que levam o jovem, de família em situação de risco social, a cometer o delito.

De acordo com Patto (2007), a escola pública, a das classes mais desfavorecidas, não consegue, com algumas exceções, oferecer oportunidades para seus alunos. A sociedade em si, já percebeu este fato, denunciado pelo baixo nível de aprendizagem dos alunos. Segundo a autora, merece destaque a total falta de produtividade do Ensino Fundamental e Médio dissimulada muitas vezes pela presença de programas assistencialistas que elevam as taxas de matrícula e as taxas de frequência, mas não oferecem boa formação intelectual.

No estudo de Gallo e Williams (2004), foi observado com destaque que a maior parte dos jovens não frequentava mais a escola e a tal fato foi atribuído os problemas surgidos dentro do espaço escolar, como desinteresse e conflitos, e que fornecem indicações da dificuldade da instituição em manter os adolescentes nela. Apontou também a dificuldade das unidades escolares em realizar a matrícula dos adolescentes 
em medida socioeducativa sob a justificativa de que tais jovens causariam ou poderiam causar problemas.

Para Chesnais (1999), a escola, mais especificamente o sistema público de ensino como fator de prevenção e repressão à criminalidade no Brasil vem falhando. Segundo o autor, para ter um desempenho eficaz a escola, além de proporcionar conhecimento intelectual, deveria propiciar meios para desenvolvimento da cidadania e desenvolvimento profissional, afirmando ainda que "A violência é fruto, mais da ignorância, que da pobreza”.

\section{Abordagem metodológica e exposição dos dados}

A execução das medidas socioeducativas nas unidades de internação no Estado do Rio de Janeiro cabe ao DEGASE (Departamento Geral de Ações Socioeducativas), sendo este órgão atualmente vinculado à Secretaria de Estado de Educação (SEEDUC). As instituições que compõem o DEGASE são responsáveis por executar as medidas socioeducativas estabelecidas pela Vara da Infância e Juventude aos jovens autores de atos infracionais cometidos no Estado do Rio de Janeiro.

Esta é uma pesquisa de natureza qualitativa, que foi desenvolvida através de um estudo de caso, com entrevistas semi-estruturadas com 05 jovens do sexo masculino, com idades entre 16 e 18 anos, escolhidos de forma aleatória, em medida socioeducativa de internação na Escola João Luiz Alves (JLA). Para tanto, foi necessário autorização da Divisão de Estudos, Pesquisas e Estágios (DEPE), da Escola de Gestão Socioeducativa Paulo Freire (ESGSE), que encaminha os pedidos de autorização ao juiz da Vara da Infância e Juventude, mediante a apresentação de projeto de pesquisa, com roteiro de entrevista e documento de confirmação de matrícula em Universidade, com autorização do Orientador e documentos do pesquisador. Não foi necessário pedir autorização aos pais e/ ou responsáveis dos jovens, pois quando em medida de internação, quem responde pelo jovem é o Estado, pois está sob sua guarda.

A Escola João Luiz Alves está localizada na Ilha do Governador, fundada em 1926 pelo então Presidente da República, Dr. Arthur Bernardes, trata-se de uma unidade de internação para adolescentes em conflito com a lei do sexo masculino. 
Os adolescentes entrevistados são apresentados aqui com nomes fictícios, a fim de preservar suas identidades. Vamos chamá-los aqui como: Vinícius, Felipe, Juliano, Pedro e Rafael. São jovens moradores de comunidades e estudantes da rede pública de ensino, municipal e estadual. Apenas um deles cursava o ensino médio quando cometeu o ato infracional e não estava em defasagem idade/ série. Os outros adolescentes eram estudantes do ensino fundamental II e haviam sido reprovados ao menos uma vez ao longo de suas vidas escolares.

\section{Resultados}

Como já foi dito, os jovens entrevistados eram do sexo masculino e tinham entre 15 e 18 anos de idade e se consideravam morenos e/ ou pardos, quando perguntados sobre qual seria sua cor/ raça, o que confirma parte do modelo do jovem em conflito com a lei descrito por Vergílio (2009) em estudo já citado que trata de temas relacionados com a juventude, a criminalidade e as medidas socioeducativas, o descreve como alguém de classificação da cor/raça declaradamente parda ou preta. No entanto, discorda do mesmo estudo, quando o mesmo também descreve os jovens em conflito com a lei como provenientes, em sua maioria como provenientes de famílias desestruturadas, pois os jovens entrevistados afirmaram que, antes de estarem cumprindo a medida socioeducativa de internação, moravam com seus pais e irmãos e que recebem visitas frequentes de seus familiares. Apenas um adolescente, de 16 anos, afirmou que morava com seu filho, em residência próxima de seus pais.

Quando perguntados se estavam estudando quando cometeram o ato infracional, dois afirmavam que não estavam e três sim. Vale ressaltar que quatro, dos cinco jovens entrevistados estavam cursando ou pararam no segundo segmento do ensino fundamental e um estava no terceiro ano do ensino médio, como afirma Vergílio (2009) que, em relação à escolaridade, o nível de escolaridade dos jovens em conflito com lei vem subindo, situando-se, principalmente, no segundo segmento do ensino fundamental e no médio.

Dentre os adolescentes entrevistados, três afirmaram que tinham mais de uma passagem pelo DEGASE, tendo a sua primeira passagem por volta dos 13 anos, em média. A maioria cumpre e cumpriu medida socioeducativa por roubo, a estabelecimentos comerciais e a transeuntes, tráfico, porte de armas e um deles por 
roubo seguido de tentativa de homicídio (“...porque eu queria dinheiro para ir ao baile funk e estava drogado e a pessoa reagiu." - como disse Rafael), aqui encontramos a ratificação das características apontadas no citado estudo de Priuli e Moraes (2007) que traçam, a partir dos prontuários, o perfil socioeconômico de jovens acautelados em uma unidade da antiga FEBEM, atual Fundação Casa, em São José do Rio Preto. Segue uma fala de Juliano, um dos entrevistados: “... eu já tava visando o playboy há um tempão, vivia aparecendo com coisa maneira, ai eu roubei mesmo, só que rodei.". Outro estava cumprindo medida socioeducativa por estupro. Quatro, dos cinco adolescentes estavam trabalhando quando cometeram o ato infracional e começaram a trabalhar, em média aos 14 anos. Apenas um deles estava legalizado como jovem aprendiz, os outros trabalhavam sem vínculo empregatício em atividades como ajudante de pedreiro, de padeiro, carregador de supermercado, auxiliar de serviços gerais e garçom. Atividades pouco remuneradas e que, segundo eles, não proporcionavam “o que eles queriam”, em bens de consumo. Tais afirmativas corroboram com a análise citada de Monares (2008) a respeito da situação política econômica que reporta à marginalização que a sociedade infringe ao jovem de classe desfavorecida economicamente, que vive em uma sociedade que estimula o consumo, mas não lhe dá os meios de satisfazer aquilo que é considerado pela mesma sociedade como padrão para ser aceito. Diante desse quadro, de uma sociedade que marginaliza aquele que não ostenta os bens de consumo e por não oferecer meios para que um dia venha a obtê-los, pois lhe é oferecida educação de baixa qualidade e as ofertas de emprego que lhe são dadas são de serviços pouco remunerados, o jovem pode encontrar nos atos delituosos formas de obter aquilo que a sociedade não the permite por meios lícitos. Todos afirmaram que nenhuma outra pessoa de suas famílias estava ou esteve em medida socioeducativa.

Quando perguntados se gostavam de sua escola e há quanto tempo estudavam, todos estudavam na mesma escola há, pelo menos, três anos e, apenas um, afirmou que não gostava da escola e da maneira como era tratado por professores e funcionários, pois, segundo o entrevistado, os alunos eram tratados com "grosseria" na escola. Apenas um dos entrevistados afirmou nunca ter sido reprovado. Tais afirmativas corroboram com a pesquisa já citada de Gallo e Williams (2004a; 2004b), que apresentou dados que corroboram com a baixa escolaridade dos adolescentes em conflito com a lei. Em um levantamento do perfil do adolescente em conflito com a lei em uma cidade do interior de São Paulo, 60,2\% dos adolescentes não frequentava a escola; outros 61,8\% tinham 
cursado da $5^{\mathrm{a}}$ à $8^{\mathrm{a}}$ série do Ensino Fundamental e 27,6\% tinham cursado até a $4^{\mathrm{a}}$ série do Ensino Fundamental. Segundo o relato desses jovens, cuja média de idade foi de 15,9 anos, os motivos que os levaram a abandonar as aulas foram: desinteresse, abandono, conflitos com outros alunos e/ou professores, fracasso escolar e suspensão das aulas.

Os adolescentes afirmaram que o que mais gostavam na escola era participar dos esportes, nas aulas de educação física, principalmente jogar futebol, pois todos afirmaram que este era o esporte que praticavam na escola, além de encontrar e conversar com os amigos. Quando perguntados sobre o que não gostavam, afirmaram que gostavam de tudo, que apenas não gostavam de acordar cedo, da diretora que não deixava jogar na quadra quando não havia aulas e de serem tratados com "grosseria" pelos professores e funcionários. Contraditoriamente, quando perguntados sobre o que menos gostavam no DEGASE, todos afirmaram que não gostavam, principalmente, de estar presos, como se pode verificar na afirmativa de Vinícius, um dos adolescentes: "gosto de todas, menos do futebol. Mas não gosto daqui, todo mundo que está aqui sabe que não está por qualquer coisa, sabe que está na cadeia porque cometeu um crime. O que eu acho de ruim daqui são os funcionários que querem que a gente acorde na bora que eles querem, querem abrir as janelas na hora que eles acham melhor. É cheio de regra, eu não gosto", e também que não gostavam de jogar futebol, pois, como afirmou Pedro: "não é como na escola, aqui tem que correr muito, cansa...”. Não houve tempo e possibilidade de assistir uma aula de Educação Física na Escola João Luiz Alves, porém, de acordo com a fala dos adolescentes, durante as aulas há uma cobrança maior sobre as regras do futebol, visto que são jovens em conflito com a lei, o que pode justificar a afirmação: "não é como na escola", e fazer com que o esporte deixe de ser tão atrativo.

Dos cinco adolescentes entrevistados, apenas um afirmou que pretende voltar a estudar, com certeza, depois que cumprir a medida socioeducativa de internação, os outros disseram que não têm certeza, pois querem trabalhar para ajudar suas famílias. Quando perguntados se pretendem seguir alguma profissão, todos afirmaram que sim e que pretendem seguir profissões como: "médico” (Felipe), “engenheiro” (Pedro), "jogador de futebol” (Vinícius), "seguir o exército" (Juliano), "ser promotor"(Rafael) e "médico veterinário" (Pedro). Justificaram suas escolhas afirmando que "É para isso que serve a escola, para ajudar a ter um futuro, ter oportunidade na vida" (Pedro), "A escola serve para aprender a escrever e a falar bem, para conseguir ter uma carreira boa"(Felipe) e "Para ter um 
futuro"(Rafael). O que ratifica a afirmativa da citada pesquisa de Feijó e Assis (2004), que afirmam que a educação aparece como variável condicionante do comportamento infracional. Vemos como a escola é posta como principal meio de se conseguir inserção social através do mercado de trabalho.

Todos os adolescentes afirmaram que mantinham bons relacionamentos com os professores e com os outros internos da JLA, de acordo com alguns, encontraram conhecidos entre os internos, pessoas que moravam próximas às localidades de suas residências. Os professores e as matérias mais citadas como as preferidas pelos adolescentes entrevistados foram a Educação Física, "Por causa dos esportes"(Vinícius) e Português "Para aprender a falar bem"(Pedro). Afirmaram que preferem os professores da antiga escola aos professores do DEGASE, mas que os respeitam, pois "Estão fazendo o serviço deles. Gostar deles eu não gosto, só gosto da minha mãe"(Juliano). E, "Do jeito que eu trato os professores, eles me tratam também"(Felipe).

A última pergunta da entrevista era se eles acreditavam que o DEGASE iria ajuda-los a não cometer mais os mesmos erros, de que forma e por que, apenas um dos adolescentes afirmou que não, que o DEGASE não teria como ajudá-lo, pois que cometeu o ato infracional foi ele e só ele poderia se ajudar, se esforçando para não cometer mais os mesmos erros. Que dependia apenas dele mesmo. Afirmou que " $O$ DEGASE não ajuda ninguém"(Rafael). Todos os outros adolescentes disseram que acreditam sim, que o DEGASE os ajudará a não cometer mais os mesmos erros, pois, segundo eles, o tempo que estão passando como internos, os ajuda a pensar e refletir a respeito do que fizeram, a pensar na vida e no que eles desejam para si. De acordo com Juliano: 'Com certeza, porque o tempo que 'nois' tá aqui, 'nois' tá como? Tá pensando no que fez, na vida, quando eu sair, vou entrar para uma igreja. Eu podia está lá fora, minha mãe podia não estar passando esse sofrimento todo. 'Nois' fica aqui dentro refletindo na vida. Eu fiz isso de bobeira, não estava precisando de nada, meu colega me chamou, ai eu fui, acabei caindo aqui dentro. Ele já tinha vindo, já esteve várias vezes aqui, já sabe como è, e segundo Rafael "Porque aqui eu estou aprendendo a viver sem drogas, eu trafiquei uma vez só, eu morei um ano na favela e trafiquei. Quando eu tentei matar a italiana, era para arranjar dinheiro para ir pro baile (funk), eu estava drogado, de maconha”.

$\mathrm{Na}$ sua maioria, esses jovens, que cometeram atos infracionais, são tratados como delinquentes por uma sociedade que o exclui, mas que, a priori, está em um sistema que tem como intuito a sua ressocialização e integração à esta mesma sociedade, para que 
possam exercer a sua cidadania plena. A instituição socioeducativa limita as atividades pedagógicas e o processo de escolarização. A escolarização, assim nos parece, está desconectada do conjunto da medida socioeducativa aplicada.

A ressignificação da escola, a partir de um projeto pedagógico que leve em consideração a realidade social e cultural desses jovens, pode ter bons resultados para o cumprimento da medida socioeducativa, estimulando a frequência e diminuindo a reincidência no "ato infracional", como deseja a sociedade como um todo.

\section{Considerações}

Ao realizar a pesquisa, observamos que há poucas publicações referentes ao tema dos adolescentes em conflito com a lei no âmbito da Educação. Observamos muitos estudos referentes à Psicologia, tratando da delinquência, e outros estudos referentes à área do Direito, analisando basicamente a aplicabilidade do Estatuto da Criança e do Adolescente, em sua maioria. No entanto, consideramos que o tema deve ser estudado também por educadores, pessoas que fazem parte da formação inicial do indivíduo e do cidadão. Analisar as características escolares dos jovens que se envolvem em atos infracionais de forma que a escola possa investigar e cuidar das influências que pode exercer na história de vida desses jovens.

Através do estudo, o que se encontra é um número reduzido de pesquisas que se aprofundem a respeito da escolarização, especialmente da trajetória escolar, do autor de ato infracional ou que se obtenha comparação de informações referentes à escolaridade deste público no tempo. Por essa razão, o que foi encontrado de significativo, e que de alguma forma pudesse agregar os conceitos de prevenção da “criminalidade" através da escola e da escolarização dos jovens em conflito com a lei foi considerado.

Observamos nos discursos dos jovens entrevistados o quanto acreditam que a escola pode ajudar a proporcionar melhor acesso ao mercado de trabalho, bens de consumo e melhores condições socioeconômicas, bem como acreditam ser essa a função da escola. Dentre os adolescentes entrevistados, apenas um deles cursava o ensino médio, não havia sido reprovado nem trabalhado, os outros quatro cursavam o segundo segmento do ensino fundamental, foram reprovados ao menos uma vez e precisavam trabalhar por diversos motivos, o que corrobora com os estudos apresentados neste trabalho. 
Como já afirmamos, há uma cultura amplamente difundida não apenas no meio acadêmico, mas na sociedade de que a escolarização é um fator de prevenção da conduta infracional. Este julgamento do senso comum não está totalmente errado. Porém ao considerar a escolarização fator de prevenção de atos infracionais, limita-se a prática destes ao estereótipo da maioria de analfabetos e semi-alfabetizados.

Consideramos que a escola não é o foco que diretamente facilita o ato infracional, pois, ao considerar a escolarização fator de prevenção da criminalidade, limita-se a prática de atos infracionais sempre ao estereótipo da maioria de analfabetos e semi-alfabetizados, entretanto a escola representa, atualmente, em razão de falta de perspectivas e oportunidades, uma variável significativa nas aspirações de jovens e esta falta de perspectivas e oportunidades faz com que a escolarização não isente o jovem da prática de ato infracional, ou seja, a escola por si só não protege contra a conduta infracional.

Buscamos compreender o efeito da escolarização nos jovens internos e como se manifestam quando estão no espaço da escola, procurando, dessa forma, determinar a sua participação na configuração da cultura escolar como sujeitos ativos. Tal configuração trata-se de um fator fundamental para a construção de um projeto pedagógico que possa romper com o binômio exclusão-punição, valorizando os direitos dos jovens e levando-os a refletir sobre o "ato infracional" praticado, considerando-os, afinal, sujeitos de sua própria história.

\section{Referências}

ASSIS, S. G.; CONSTANTINO, P. Perspectiva de prevenção da infração juvenil masculina. Ciências e Saúde Coletiva, v.10, n.1, p.81-90, 2005.

ASSIS, Simone Gonçalves de; SOUZA, Edinilsa Ramos de. Criando Caim e Abel: pensando a prevenção da infração juvenil. Ciênc. saúde coletiva, Rio de Janeiro, v. 4, n. 1, 1999.

CANO, Ignacio. Políticas de segurança pública no Brasil: tentativas de modernização e democratização versus a guerra contra o crime. Sur, Rev. int. direitos human. São Paulo, v. 3, n. 5, 2006. 
CHESNAIS, Jean Claude. A violência no Brasil: causas e recomendações políticas para a sua prevenção. Ciênc. saúde coletiva, Rio de Janeiro, v. 4, n. 1, 1999.

COSTA, Cláudia Regina Brandão Sampaio Fernandes da; ASSIS, Simone Gonçalves de. Protective factors for adolescents in conflict with the law within the socialeducational context. Psicol. Soc. , Porto Alegre, v. 18, n. 3, 2006.

DRYFOOS, J. Adolescents at Risk. Oxford University Press, New York, 1990.

ESPÍNDULA, Daniel Henrique Pereira, SANTOS, Maria de Fátima Souza. Representações sobre a adolescência a partir da ótica dos educadores sociais de adolescentes em conflito com a lei. Psicologia em Estudo, 9(3), Maringá, set/dez, 2004.

FANDINO MARINO, Juan Mario. Análise comparativa dos efeitos da base socioeconômica, dos tipos de crime e das condições de prisão na reincidência criminal. Sociologias, Porto Alegre, n. 8, 2002.

FEIJO, Maria Cristina; ASSIS, Simone Gonçalves de. O contexto de exclusão social e de vulnerabilidades de jovens infratores e de suas famílias. Estud. psicol. (Natal), Natal, v. 9, n. 1, 2004.

GALLO, A. E., WILLIAMS, L. C. DE A. A escola como fator de proteção à conduta infracional de adolescentes. Caderno de Pesquisa, v.38 n.133, p. 41-59, 2004.

GARCIA, Mauricio, MADRIAZA, Pablo. Sentido y sinsentido de la violencia escolar: análisis cualitativa del discurso de estudiantes chilenos. Psyche, 14(1), Santiago, maio, 2005.

MONARES, Andrés. Neoliberalismo, marginación y delincuencia juvenil. Polis, Revista de la Universidad Bolivariana, 19, Santiago, 2008.

PATTO, Maria Helena Souza. Escolas cheias, cadeias vazias: nota sobre as raízes ideológicas do pensamento educacional brasileiro. Estud. av. , São Paulo, v. 21, n. 61, 2007.

PRIULI, Roseana Mara Aredes; MORAES, Maria Silvia de. Adolescents in conflict with the law. Ciênc. saúde coletiva, Rio de Janeiro, v. 12, n. 5, 2007. 
SCHOEMAKER D. J. Theories of Delinquency. An Examination of Explanations of Delinquent Behavior. Oxford University Press, New York, 1996.

SPERGEL I. A. \& CURRY G. D. Strategies and perceived agency effectiveness in dealing with gang problems. CR Huff, Gangs in America. Sage,Newbury Park, California, 1990.

VALENCIA, Maria Cristina Palacio. La Delincuencia Juvenil: un reto para descifrar una metáfora relacional. Eleuthera, 5, jan.-dez., 2011.

VERGILIO, S.S. Elevando a tensão geral: o aumento da escolaridade de adolescentes autores de atos infracionais em medida de internação provisória no estado do Rio de Janeiro. Dissertação de mestrado. Universidade Federal do Rio de Janeiro, 2009. 